\title{
LABTC enquanto espaço de criação e pesquisa sobre traje de cena: ensino, pesquisa em gênero.
}

O presente artigo busca evidenciar os resultados pré - liminares de pesquisa realizada pelo LABTC- Laboratório de Pesquisa sobre Traje de Cena nas investigações realizadas no primeiro ciclo de pesquisa. O LABTC é um espaço investigativo de pesquisa ligado ao departamento de Arte Cênicas da Universidade Federal do Maranhão que buscou em sua primeira investida cientifica tencionar as questões sobre o traje de cena e gênero mantendo contato direto com a disciplina de prática de encenação do curso de Licenciatura em Teatro. A estruturação prática e teórica da investigação é dada no livre exercício dos alunxs figurinistas com contato direto com o todo o processo criativo que envolve a criação da cena.

Palavras chaves: Traje de cena, Teatro, Criação, Gênero

LABTC as a space for creation and research on scene costume: teaching, research on gender.

The present article seeks to highlight the preliminary results of research carried out by LABTC - Research Laboratory on Scene Costume in the investigations carried out in the first research cycle. The LABTC is an investigative research space linked to the Department of Performing Arts of the Federal University of Maranhão, which sought in its first scientific investiture to discuss the questions about the costume of scene and genre maintaining direct contact with the discipline of practice of staging the course of Licenciatura in Theater. The practical and theoretical structuring of the investigation is given in the free exercise of costume designers alunx with direct contact with the whole creative process that involves the creation of the scene.

Keywords: Scene Costume, Theater, Creation, Genre Keyword: Costume, Theater, Creation, Genre

\section{Escolha do tecido - Introdução}

Pensar figurino teatral é articular-se diretamente com o corpo dos sujeitos que os veste, assim como é também pensar em direcionamentos que compreendem o gênero binário nas demarcações das indumentárias.

Antes de iniciarmos alguns apontamentos com relação aos resultados encontrados no primeiro ciclo do LABTC - Laboratório de pesquisa sobre traje de cena, é interessante percebemos como a conceituação de figurino teatral, por vezes vinculada ao termo traje de cena, vem sendo trabalhado por alguns estudos que se dedicam a sedimentar o referido conceito como espaço de pesquisa e investigação.

Segundo o dicionário do teatro a primeira forma de uso do figurino, é: 
Como o traje, o figurino serve primeiramente para vestir, pois a nudez, se não é mais, em nossos palcos, um problema estético ou ético, não é assumida com facilidade. O corpo sempre é associado pelos ornamentos ou pelos efeitos de disfarce ou ocultação, sempre caracterizado por um conjunto de índices sobre a idade, o sexo, a profissão ou classe social.” (PAVIS, 2015, p. 168)

Mesmo reconhecendo os avanços que o figurino obteve com o entendimento das visualidades da cena como parte integrante da encenação, o pesquisador Patrice Pavis ressalta sua função primária de vestir o sujeito demarcando valores socialmente descritivos por normas sociais e culturais.

O Jean- Jacques Rubine, em 1982 no livro a Linguagem da encenação teatral apresenta a seguinte definição:

O Figurino, por sua vez, deve ser considerado como uma variedade particular do objeto cênico. Pois se ele tem uma função especifica, a de contribuir para a elaboração do personagem pelo ator, constitui também um conjunto de formas e cores que intervêm no espaço do espetáculo, e devem portanto integra-se nele (RUBINE, 1982, p.127)

Outra concepção de figurino ou traje teatral está no emprego da mudança de nome para traje de cena realizada pelo pesquisador Fausto Viana. Para o pesquisador, os referidos termos já não retratam a multiplicidade que o campo cênico abriga. Segundo o Viana, "traje de cena é um termo mais amplo que o traje teatral, podem abranger trajes de teatro, dança, circo, mímica , performance ( no sentido e que a tratamos aqui), show, espetáculo” ( VIANA, 2014, p. 27).

Diante de todas as colocações que Fausto Viana faz ao destacar sua visão sobre traje de cena, o referido pesquisador coloca alguns pontos que ele reconhece como indicativos da função do figurino no ato cênico.

De forma quase também quase que óbvia, um figurino pode indicar, de maneira geral: localização espacial ou geográfica;clima , época do ano; idade da personagem; sexo; ocupação, posição social e atividade; a hora do dia e a ocasião; período histórico em que a personagem vive; fatores psicológicos. (VIANA, 2014, p. 28, grifo meu).

Faço destaque da palavra sexo na citação do autor, pois ela nos leva a grande questão da pesquisa desenvolvida no primeiro ciclo do LABTC por meio do questionamento: Se o figurino teatral não tivesse a função de demarcar o sexo (e por conseqüência o gênero) da personagem, quais outras vias de construções poderiam ser apresentadas no ato da criação do mesmo?

Mediante esta questão apresento neste texto a estruturação da pesquisa e seu desenvolvimento até o presente momento. Primeiramente, está pesquisa esta vinculada ao meu campo de ensino na categoria de professor efetivo da Universidade do Estado do 
Maranhão, pois as disciplinas ligadas ao meu concurso compreendem no que entendemos hoje sobre visualidades da cena. Atuo nas disciplinas de cenografia e caracterização (figurino e maquiagem). O espaço investigativo também se apresenta enquanto campo investigativo do meu curso de doutoramento desenvolvido no programa de pós- graduação em teatro da Universidade do Estado de Santa Catarina UDESC/PPGT que versa sobre metodologias de criação do traje de cena a partir de questões em gênero.

\section{Primeiro corte - LABTC}

Propor um espaço formativo como o LABTCE- Laboratório de Pesquisa sobre Traje de Cena em diálogo efetivo com os discentes do curso de teatro,é dispor a eles um ambiente de experimentações das questões emergentes do próprio ato de pensar, criar e desenvolver na perspectiva do figurino teatral/traje de cena em consonância com a cena contemporânea, visto que as pesquisa desenvolvidas no espaço do laboratório serão permeadas por diálogos constantes com as disciplinas de encenação e interpretação I,II e III ${ }^{1}$.

Pensar o ator criativo na investigação e elaboração do traje de cena de acordo com questões contemporâneas em gênero nos coloca em justaposição com questões emergentes do nosso tempo, seja elas localizadas no tempo social que nos constitui como individuo ou desenvolvida no campo artístico que se torna um reflexo daquilo apresentado ao campo social.

Diante deste cenário, e ao entrar na instituição enquanto docente idealizo o grupo de pesquisa LABTC- Laboratório de pesquisa sobre Traje de Cena, ligada ao departamento de artes cênicas da UFMA. Início as atividades da pesquisa investigativa em caráter de tese tendo o laboratório como o principal meio de articulação da pesquisa com os alunos e alunas ligados ao curso de Teatro Licenciatura.

A escolha metodológica da investigação é a Pesquisa - Ação na medida em que a referida opção metodológica oportuniza os praticantes da pesquisa a desenvolver um projeto investigação com freqüente avaliação durante as etapas do processo.

Desta forma, a pesquisa por si só assume a importância do risco ligada ao processo na medida em que uma das ações mais interessantes na investigação; que se propõem a apresentar novas possibilidades de criação do figurino teatral desvinculado a

1 Disciplinas ligadas ao projeto político pedagógico do curso de Licenciatura em Teatro da Universidade do Estado do Maranhão - UFMA. 
questão de gênero são as etapas de avaliação constantes entre os sujeitos efetivos do processo, ou seja, alunos, alunas e mediador da pesquisa.

\section{Modelando o traje - Articulações entre gênero e traje de cena}

A vestimenta enquanto estrutura modal criada com objetivo de vestir o indivíduo é descrita socialmente por meio de valores sociais de significados e significantes que atuam em estruturas binárias no que concerne a demarcação de gênero por meio da roupa. No desenvolvimento da criação e produção da vestimenta, a divisão por gênero é naturalmente percebida no viés masculino e feminino, reforçada por modelagens específicas para cada zona binária descrita anteriormente, já que a base corporal da roupa perpassa por aspectos que legitima, apenas, o masculino e o feminino.

Ou seja, as regras direcionadas à vestimenta estão convencionadas por normativas e confluências de fatores que delimitam a expressividade do corpo mediante a expansão do gênero, para além do pensamento binário, e que são definidas nas demarcações de gênero que devem emergir da vestimenta. Nesse sentido, a vestimenta ultrapassa seus objetivos de apenas vestir o indivíduo, passando a ser observada como um estrato social fundamental para a demarcação do gênero por meio das estruturas da roupa diante de algumas conjunturas da matriz cultural de cada período histórico e social.

Sendo assim, a estrutura que compõe o status social da vestimenta, seja na dimensão simbólica ou estrutural, de forma sistemática adentra o campo da criação artística por meio das normativas que são ressaltadas em diversas etapas da criação do traje de cena pelo figurinista ou por indivíduos que se propõem a criar um traje cênico. Levados por essa afirmativa, a referida questão emerge dessa constatação: Como pensar o traje de cena sem deflagrar a ele aspectos de gênero? Podemos pensar formas de criação do traje de cena mantendo a funcionalidade do figurino buscando uma demanda de figurino agender?

Impulsionados por está questões resolvemos propor um ambiente formativo para os licenciados em teatro da Universidade Federal do Maranhão, onde através do LABCET criações e experimentações irão emergir por meio de novas propostas metodológicas que adentrem de forma sistemática as novas questões de gênero para com a vestimenta cênica, na busca de articular a pesquisa em artes cênicas a demandas do nosso tempo. 
As primeiras experiências criativas foram desenvolvidas no segundo semestre do ano de 2017 na disciplina de prática de encenação ministrada pela professora Dr $^{\mathrm{a}}$ Michelle Cabral. A partir dos projetos de encenação dos alunos (as) encenadores(as) da referida disciplina os alunos(as) figurinistas do LABTC desenvolveram uma proposta de figurino Agender.

Os projetos de encenação tiveram como base dramatúrgica os textos Hotel Jasmim de XXXX e A mulher que digita da XXXXX ambas as dramaturgias contemporâneas retiradas da coletânea de novas dramaturgias da cidade São Paulo.

\section{Primeiro prova - Traje na cena}

Diante dos projetos de encenação cada aluno (a) figurinista teve a oportunidade de fazer a leitura do argumento do aluno encenador, e a partir das informações escolheram os projetos para se filiar na buscar de criar um figurino teatral que se alinhasse com as escolhas estéticas do aluno encenador.

A partir da escolha os alunos (as) figurinistas se envolveram diretamente no processe de montagens das cenas se articulando com a direção da cena e todos os sujeitos das visualidades da cena: cenógrafo e iluminador de cada cena. Os processos de ensaio tiveram a presença dos figurinistas, efetivando assim o contato direto com o processo criativo da cena, pois não existe criação de traje de cena sem que o figurinista entenda as razões teóricas e prática da cena que são formuladas na sala de ensaio.

No percurso do LABTC tivemos a participação de cinco alunos, sendo que dois desistiram do processo por razões pessoais antes mesmo de entrar no processo criativo dos trajes de cena. Sendo assim, finalizamos com três projetos de traje de cena sendo eles: O projeto do aluno pesquisador figurinista Ivo Borgneth aluno do sexto período do curso de Licenciatura em Teatro, Silvio Renan aluno do sétimo período do curso de Artes Visuais e Nuilane Lago aluna do quinto período do curso de Artes Visuais. Para este recorte textual será evidenciado apenas os processo criativos dos dois primeiros alunos.

Vale ressaltar, que mesmo o projeto sendo ligado ao departamento de artes cênicas ele recebe alunos de outras graduações interessados na temática central do grupo.

Diante do exposto vou agora apresentar os resultados criativos oriundo do espaço de pesquisa criativa LABTC, pontuando os argumentos criados por cada aluno 
figurinista a fim de apresentar as primeiras possibilidades de articular a criação do traje de cena com questões contemporâneas em gênero.

Todos os relatos aqui colocados na descrição do processo criativo, assim como os principais desafios desenvolvidos pelos alunos e alunas figurinistas, foram extraídos do diário dos figurinistas que eles desenvolveram ao logo de todo o processo de estudo, pesquisa e criação. Este recurso foi usando enquanto espaço de registro para as ações e resultados desenvolvidos não somente no processo criativo como em todo o processo formativo do LABTC que antecederam a criação do traje de cena.

\section{Processo 01 - Figurinista Pesquisador Silvio Renan}

\section{Texto: A mulher que digita}

\section{Encenadora: Jairiane}

O aluno pesquisador Figurinista Silvio Renan escolheu o projeto cênico da aluna encenadora Jairiane Diniz que trabalhou com o texto "A mulher que digita”, com uma atriz do gênero feminino em uma cena na categoria de monologo, tendo visões estéticas voltadas ao estilo Brechistiano.

Segundo o aluno figurinista, o que mais chamou atenção dele e de certa forma o que o direcionou para escolher o projeto da aluna Jairiane, diante do universo de projeto que recebemos da disciplina de prática de encenação, foi o titulo dado ao recorte da dramaturgia: Na pele. Segundo ele, era um titulo muito desafiador: "Na pele... pensei: nossa, isso é muito conveniente com o que queremos, ou com o que eu quero, quero vivenciar isso na pele....” (Trecho do diário do figurinista) . Neste momento, creio que o aluno faz uma referencia direta as questões desenvolvidas no LABTC e que estão direcionadas a vivencia na pele, ou sobre a pele, onde se porta o traje de cena. Quando ele menciona "vivenciar isso na pele", e como ele se colocasse diante do desafio de desenvolver um figurino que efetivasse as dimensões em gênero pontudas no LABTC enquanto exercício prático voltado para a cena.

No primeiro contato do figurinista com a direção da cena, relatado no diário do figurinista, a diretora pontua que para ela o figurino deveria acompanhar a perspectiva Brechtiana $^{2}$ dada por ela à cena. Diante disso, o aluno figurinista se viu em meio a duas questões: a primeira em desenvolver a ideia sem fugir das pretensões estéticas e de atuação dada pela diretora, e a outra questão era trabalhar com ideia focal do LABTC

2 Referencia direta aos estudos do poeta e dramaturgo Bertolt Brecht. 
que era desenvolver uma proposta com articulações em gênero por meio do traje de cena.

Segundo a diretora da cena o figurino deveria ser:

\begin{abstract}
Algo que não fosse considerado bonito, mas que fosse esteticamente simples... que tivesse uma mensagem simples e ao mesmo tempo carregada de significado que passasse características de Dalva e da Deta, onde público enxergasse e diferenciasse não só pela cena, mas pelo figurino.(Trecho retirando do diário do figurinista)
\end{abstract}

Por meio de inúmeros contatos com a direção sobre a proposta inicial do figurino, e por meio de referências encontradas nos acompanhamentos de alguns ensaios o aluno figurino chegou a uma proposta onde as questões de gênero fossem desenvolvidas por meio da modelagem, e a dimensões estéticas sugeridas pela diretora fossem efetivadas pelas escolhas de tecidos, e detalhes colocados na vestimenta. Mesmo parecendo um pensamento dicotômico, mas no ato da criação as relações entre estética e liberdade criativa estavam entrelaçadas no mesmo objetivo.

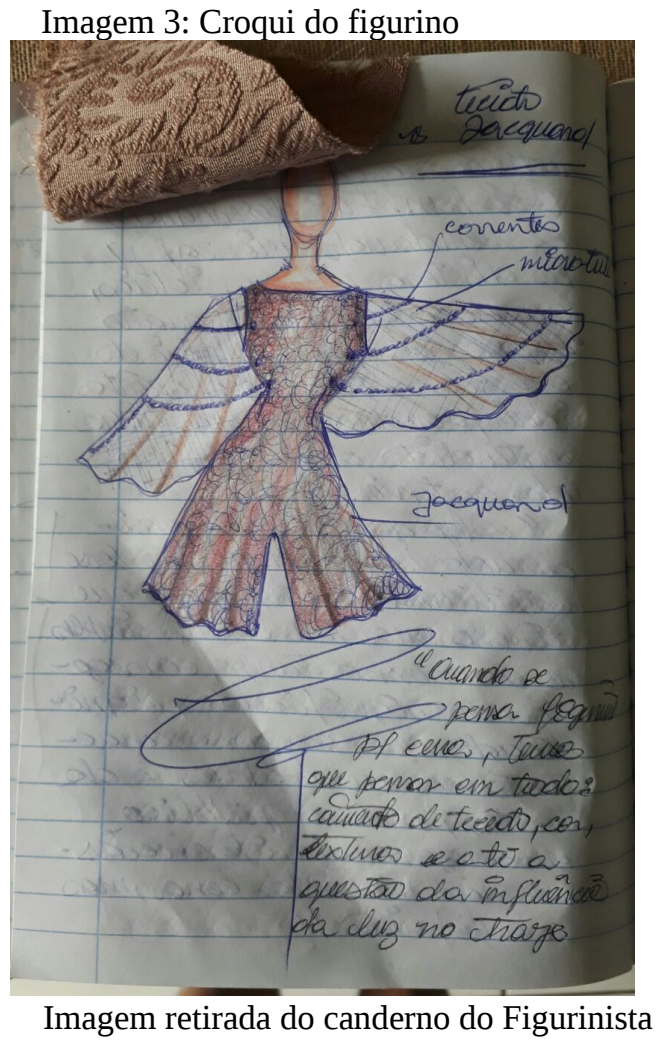

Segundo o argumento do croqui desenvolvido pelo aluno figurinista sua ideia era criar: 
Um macaquinho que não marcasse ou pelo menos não evidenciasse o corpo da atriz. Pensou também no elemento cor, a cor nude para remeter ao titulo da cena "Na pele", e remeter a passagem do texto em que a personagem estimula as mulheres "a saírem de suas casas porque os seus filhos estão sendo mortos”, dando aspecto de se desconbrir-se, saindo dos seus confortos. No que corresponde ao tecido e a textura pensei em algo eu fosse confortável e que "armasse” um pouco para criar efeito de certo volume nas pernas do macaquinho. Sobre a textura foi pensado em algo que trouxessem elegância ao figurino chegando em texturas em jacaunas. .(Trecho retirando do diário do figurinista)

Para as idéias de modelagem de mangas morcegos confeccionadas em tule e com detalhes em correntes, foram usadas referencias psicológicas da personagem extraídas do estudo aprofundado do texto, assim como referencias nas movimentações do corpo da atriz observadas nos ensaios. Segundo o figurinista:

\begin{abstract}
A ideia de micro tule para as mangas estilo morcego é um pouco complexa mas vala apenas argumentar. A ideia da asa de morcego enviezadas, foi pensando nesse tecido, primeiro pelo aspecto de pele que ele denota e segundo porque o mesmo possui excelente caimento para a ideia, e terceiro que vem determinar momentos da personagem Dalva, pois tem um momento de certa "histeria” ou "loucura” então evidenciamos essa manga com esse aspecto de liberdade pela nudez e aprisionado pelas correntes e um outro elemento que vale destacar é que essas mesmas mangas deveriam passar a ideia de camisas de forças. (Trecho retirando do diário do figurinista)
\end{abstract}

Desta forma, os usos dos materiais usados na confecção do figurino assim como as modelagens sugeridas foram pensada em justaposição com as questões colocadas no texto pela personagem; estética levantada pela encenadora. A ideia era que o figurino determinasse o gênero da personagem, mas que continuasse a exercer o papel de traje como um balizador simbólico desenvolvido na cena.

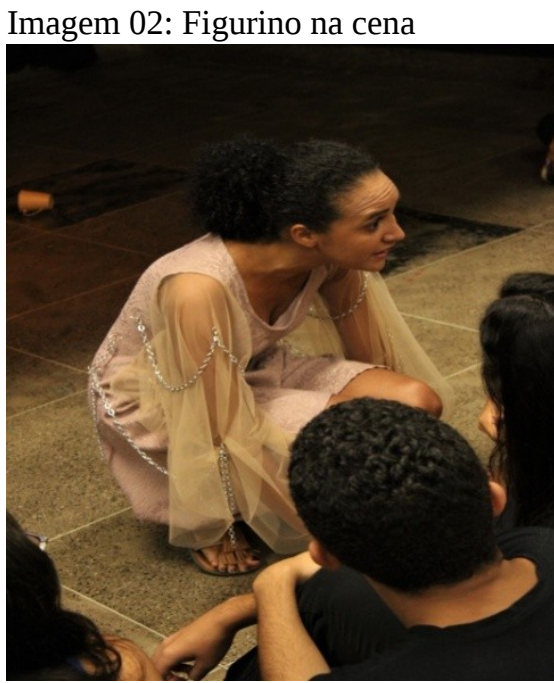

Arquivo LABTC
Imagem 03: Atriz com o figurino

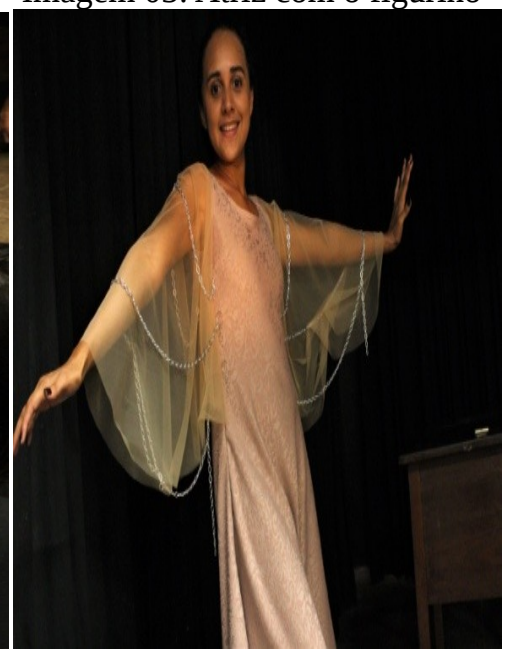

Arquivo LABTC 


\section{Processo 02 - Figurinista Pesquisador Ivo XXXX}

\section{Texto: A mulher que digita}

\section{Encenadora: Renan XXXXX}

O aluno pesquisador figurinista Ivo Borgneth realizou seu processo criativo por meio da dramaturgia de "Hotel Jasmim", diante do projeto de encenação do aluno diretor Renan Breckman. O projeto de cena buscou retratar a atmosfera dada no texto para o ano de 2047 por meio de um efeito futurista.

Uma das primeiras ações do processo criativo do aluno figurinista foi recorrer ao plano de imagens que lhe desse referencias de cores, formas e até texturas diante da referencia principal que era chegar a uma ideia futurista por meio do figurino acompanhando assim a ideia cenografica, e de iluminação descrita no plano de encenação do aluno diretor.

De inicio o aluno figurinista restrata que não ficou pensando na questão de genero como primazia do ato criativo:

\footnotetext{
Pensei em não pensar com o gênero do personagem (ambos os personages do texto são do gênero biologicamente reconhecidos como masculinos) e ver como eu poderia ressaltar algo atraente no corpo do personagem que fosse comum para ambos os gênero. (Trecho retirando do diário do figurinista)
}

Fique evidente por meio dessa passagem continda no diário do referido figurinista que mesmo não pensar fixamente em gênero, a configuração se apresenta para ele até nas resoluções que eles acha que estam fazendo sem levar em consideração a questão de gênero.

Essa passagem denota outro desefio percebido no ato criativo de uma proposta como esta na medida em que ao desenvolver um figurino sem gênero não quer dizer que estou desistituindo o persomagem de ter gênero. A grande tarefa do figurinista está nos reacordos que ele trava no processo criativo. Um figurino sem genero não destitui o gênero do personagem seja feminino ou masculino. Ele apenas pontua que a roupa daquele ou daquele personagem não tem o objetivo de definir seu gênero ou seja, a instância da roupa não demarcar o gênero de forma binaria.

Retornando ao processo criativo proposto pelo aluno Ivo XXX por meio da demanda de criar um figurino com tempo histórico demarcado nos anos de 2047 dando a entender ao público uma ideia futurista e ainda com conexoes em gênero não binarios ele desenvolve a seguinte ideia. 
Levando em consideração as exigências resolvi fazer o figurino do Fernando (michê) de maneira em que a sexualização do corpo dele se tornasse possivel por meio do uso de transparencias.Opitei por fazer um short trasparente e um Cropped afim de acentuar a barriga do ator. Optei fazer uma prospota que pudesse ser usada por ambos os sexos. Para o figurino do Jorge optei pela calça trasparente, porém sem mostrar muito o corpo. No figurino de Jorge usei de artificios que seriam desenvvolvidos na propria cena para que ao final da cena o traje dele se tranformace e virasse o mesmo do Fernando para acompanhar a mudança psicologica da personagem. (Trecho retirando do diário do figurinista)

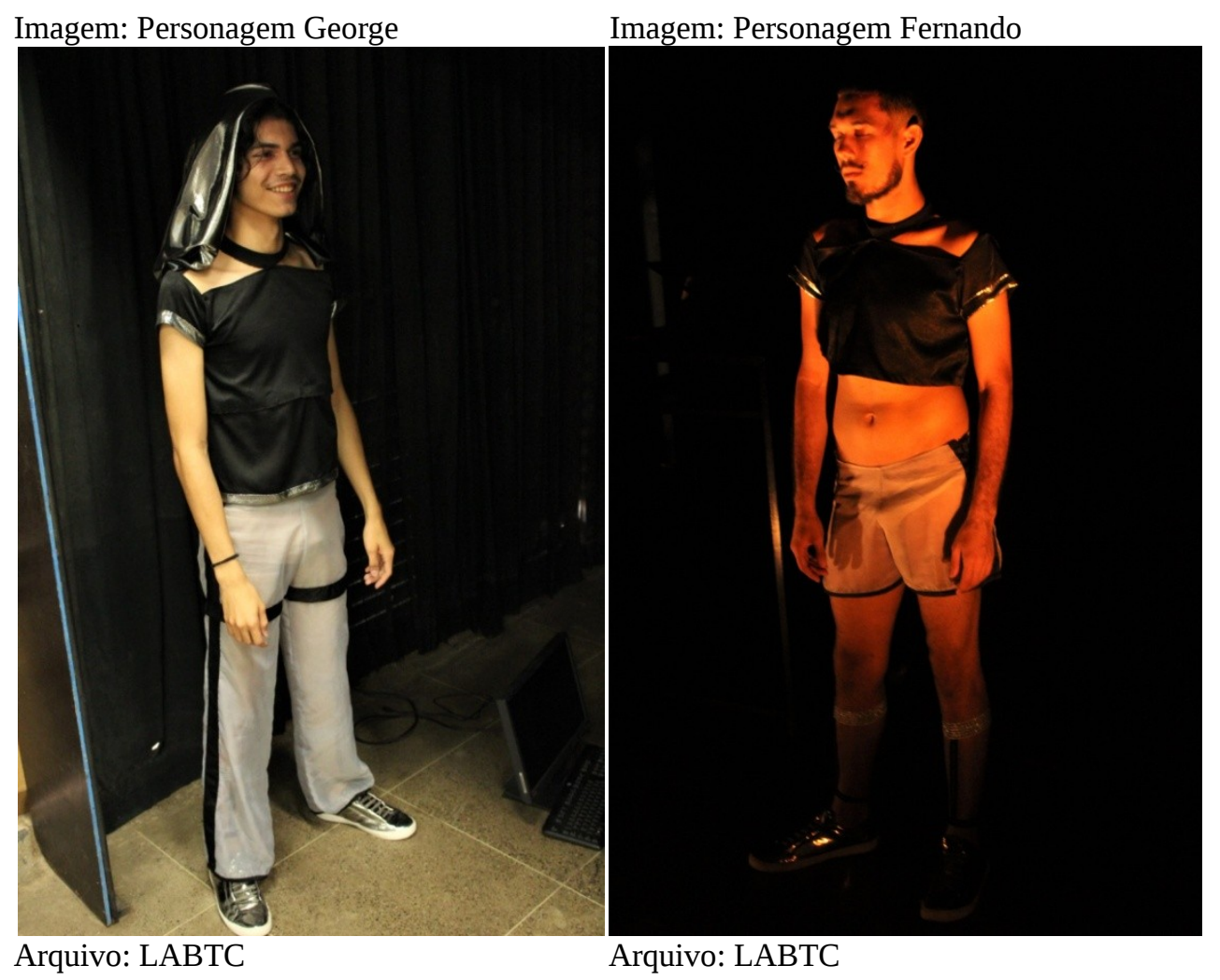

Ao analisar o trabalho do Ivo e diante do que ele apresenta no diário do figurinista ele buscou acentuar sue trabalho também uma criação com aspecto de discutir uma proposta agender por meio da modelagem trabalhando com convenções atribuídas ao uso do short e ao uso do Cropred. A temporalidade da dramaturgia foi usada ao seu favor no processo criativo porque de forma direta lhe jogou uma abertura, mas ampla pensando que umas das projeções do futuro com relação a roupa fosse atribuída ao não uso do binarismo de gênero por meio da roupa.

\section{CONCLUSÃO}

A ideia inicial do laboratório ao promover a articulação pedagógica entre LABTC e a disciplina de encenação do curso de Licenciatura em Teatro da 
Universidade Federal do Maranhão era de fato propor um campo de experimentação que se aproximasse do campo de exercício do figurinista que é o ato criativo voltado para a cena na busca de efetivar contato com toda a rede de articulações que envolve a encenação, ou seja, o diretor, os atores, o iluminador, o cenográfico.

Desta forma, as redes de negociação acontecem e se renovam nas transformações no ato do exercício de criação artística. Sendo assim, a primeira instância do estudo prático do LABTC foi efetivamente desenvolvida já que os alunos pesquisadores figurinistas se entregaram ao processo criativo desenvolvendo todas as redes de negociação que o sujeito criador, ou seja, o figurinista tem que passar para que seu projeto também ganhe forma na cena.

Eu como mediador deste processo deixei com que eles ficassem livres para criar, sabendo conviver com as frustrações, e acontecimentos inesperados. O processo criativo é aberto e passivo diante do cenário de realidade para que ele aconteça ou não. São inúmeros os fatores que emergem nas escolhas criativas, e foi de fato isso que mais pode ser percebido nas criações deste primeiro ciclo do LABTC.

O risco, o medo de errar fez com que os alunos e alunas figurinistas se permitissem efetivar a criação sobre a ótica investigativa de olhar "aversamente" o processo criativo do traje de cena.

A forma que cada uma olhou para o seu processo criativo ao pensar ele na constante relação entre traje de cena e gênero ou ausência dele foi o mais inventivo neste processo, pois projetou o aluno pesquisador a perceber que no ato da prática em pesquisa que suas constatações são aprofundadas ou refurtadadas.

Ou seja, pensar o figurino agender é elevar suas certezas binárias em gênero por meio da roupa ao um patamar em que possa fragiliza- las a cada avanço no processo de investigação do texto e estudo horizontalizado de cada personagem. Nas duas criações criativas desenvolvidas aqui enquanto resultado, a priore, da pesquisa em andamento pelo LABTC, a rede de negociação se deu por meio de efetivar novos pensamentos através da modelagem, buscando formas e experimentando meio na busca de resultados preliminares que só se revela no campo da experimentação continua.

\section{Referencias}

VIANA, Fausto. Traje de cena, traje de folguedos. Estação das Letras. São Paulo 2014. PAVIS, Patrice. Dicionário de Teatro. Perspectiva. São Paulo. 2015

ROUINE, Jean - Jacques. A linguagem da encenação teatral. Zahar Editores, 1982. 